\title{
TRAJETÓRIAS RELIGIOSAS: percursos de pais e mães de santo do candomblé
} em João Pessoa ${ }^{1}$

\author{
RELIGIOUS TRAJECTORIES: candomble priests life histories in João \\ Pessoa-PB-Brazil
}

Gracila Graciema de Medeiros*

\section{Resumo}

Estudar as trajetórias religiosas de pais e mães de santo do candomblé em João Pessoa, constituiu-se na temática desta pesquisa, cujo objetivo foi compreender elementos pontuais do trânsito religioso na cidade de João Pessoa, a partir da busca e adesão ao candomblé. Para isso, observa-se trajetórias de vida religiosa e o movimento de cada trajetória, dentro e fora do campo afro-brasileiro de cinco agentes, pais e mães de santo do candomblé. O diálogo com a sociologia praxiológica de Bourdieu foi o ponto de ancoragem da reflexão. Os conceitos de habitus, campo e trajetória tornam-se centrais para o quadro descritivo-analítico, assim também como os pressupostos da sociologia que se utilizam dos conceitos de experiências socializadoras e disposições. Esta investigação se caracteriza como uma pesquisa qualitativa, cujos dados foram coletados por meio de entrevista semiestrutura. A análise das trajetórias dos sujeitos constrói um percurso delineado como individual, que, porém, mostra-se atravessado continuamente pelas forças sociais, disputas, conflitos, mudanças e tendências que atuam no campo em questão.

Palavras-chave: Trajetórias Religiosas; Pais e Mães de Santo; Candomblé; João Pessoa.

\begin{abstract}
Studying the religious trajectories of priests of candomble in João Pessoa was the theme of this research, whose objective was to understand specific elements of religious traffic in the city of João Pessoa, from the search and adherence to candomble. For this purpose, it was observed the trajectories of religious life and the movement of each trajectory, inside and outside the Afro-Brazilian field of five agents, priests (known as father and mother of saint) of candomble. Dialogue with Bourdieu's praxiological sociology was the anchor point of this reflection. The concepts of habitus, field and trajectory become central to the descriptive-analytic frame, as well as the sociological theories that use the concepts of socializing experiences and dispositions. This investigation, a qualitative research, collected data through semi-structured interviews. The analysis of the subjects' trajectories builds an individual path, which, however, is continuously crossed by the social forces, disputes, conflicts, changes and trends that act in the fieldwork.
\end{abstract}

Keywords: Religious trajectories; African-Brazilian Santeria; Candomble.

\footnotetext{
${ }^{1}$ Este artigo foi elaborado a partir de dissertação de mestrado apresentada ao Programa de Pós-Graduação em Sociologia (MEDEIROS, 2016).

* Aluna de doutorado em Sociologia - PPGS/UFPB/Brasil. E-mail: gracilagra@ hotmail.com
} 


\section{0 campo religioso afro-brasileiro}

O objetivo deste texto é refletir sobre o cenário religioso afro-brasileiro em João Pessoa, destacando os deslocamentos (emissão e recepção) de adeptos entre as denominações, internas e externas a ele. Procura descrever e analisar a trajetória de vida religiosa e o movimento de cada uma, dentro e fora do campo afro-brasileiro de cinco agentes, pais e mães de santo de candomblé, colocando em evidência as diversas “estações" pelas quais passaram antes de chegar à denominação em que se encontram. O material empírico foi produzido por meio de observação participante em terreiros de candomblé da cidade de João Pessoa, e entrevistas semiestruturadas com seus titulares, sendo uma mãe de santo e quatro pais de santo. Os dados foram produzidos no ano de 2015 quando eu realizava a pesquisa para a dissertação de mestrado. Um dado interessante para quem vai ler esse texto: minha posição de fala é de uma mulher aparentemente branca, estudante universitária (doutoranda em sociologia), oriunda do catolicismo e de sua militância, e há quase dez anos, adepta do candomblé de nação ketu, no qual, recentemente, fui iniciada "com cargo de ekedi". Com estes esclarecimentos iniciais, fica fácil perceber que a trajetória religiosa da autora é o seu próprio objeto.

Para melhor compreender o campo religioso afro-brasileiro, e a adesão dos indivíduos ao candomblé, é necessário entendermos alguns elementos que o compõem.

Primeiramente, deve-se dar ênfase à perda de hegemonia do catolicismo, que passa a disputar fiéis com as demais religiões. Essa perda, em números oficiais pode ser compreendida de outra forma, afinal denominações como a jurema, o candomblé e a umbanda passaram a ser classificadas como religiões. Elas compõem parte considerável do campo afro-brasileiro na cidade de João Pessoa, por isso é necessária uma breve apresentação de cada uma, com destaque especial para o candomblé por se tratar do nosso objeto de estudo.

Uma visão geral do campo religioso afro-brasileiro em João Pessoa, em se tratando do que Giobellina Brumana (2013) chama de "cultos subalternos", três expressões são as mais fortes: o catimbó/jurema, a umbanda e o candomblé. É importante ressaltar que o campo afro-religioso (tanto local quanto nacionalmente) não se encerra nestas três possibilidades. 
Em João Pessoa, três são as denominações principais do campo em foco: Catimbó/Jurema, Umbanda e Candomblé. Para efeito da pesquisa, sugerimos que a sua formação/consolidação se dá em três períodos.

O primeiro estende-se dos registros iniciais do Catimbó até o final da década de 1950. Nele, predominaram as mesas do Catimbó-Jurema, marcadas pela influência kardecista e do catolicismo popular.

O segundo, a partir de 1960, é o período de chegada e expansão da Umbanda, quando ela passa a incorporar o Catimbó/Jurema e surgem as federações do culto.

E por último, o período que se estende da segunda metade da década de 80 aos dias atuais, marcado pelo surgimento dos primeiros terreiros de Candomblé e pela constituição de discursos delineadores de reconhecimento e legitimidade interna e externamente ao campo. Sedimentam-se formas de enfrentamento e diálogo com outras religiões, com o poder público e a sociedade em geral. O campo se expande com a abertura de novos terreiros, facilitado pelo pluralismo religioso e pela liberdade de culto (GONÇALVES; FERREIRA, 2012, p. 2).

Os parâmetros históricos acima mostram a formação do campo afro-religioso na cidade, que só se torna de fato um campo - segundo o conceito de Bourdieu (1989) -, depois da chegada da umbanda, quando passam a acontecer disputas de poder, disputas por espaço, disputas por fiéis, clientes ${ }^{2}$ e disputas no plano místico/espiritual, além da institucionalização de normas específicas quanto ao comportamento das agências e agentes.

No contexto de delineamento do campo afro-religioso na Paraíba, vale desatacar alguns marcos históricos importantes que apontam para sua institucionalização:

Em 1966, ocorreu a promulgação da Lei Estadual 3.443 de 6 de novembro que tornou "livre o exercício dos cultos africanos em todo território do Estado da Paraíba, observadas as disposições constantes desta lei”. Neste mesmo ano, surgiu a Federação dos Cultos Africanos do Estado da Paraíba (FECAB) (GONÇALVES; FERREIRA, 2012, p. 3).

A umbanda, então, consolida-se no estado da Paraíba, e sua principal fonte de influências é Recife, vinda das mãos de famosos sacerdotes como Mario Miranda, Zé Romão e Pai Edu (faziam ritos que mesclavam a umbanda com o nagô pernambucano) que iniciaram muitos pais de santo umbandistas de João Pessoa. Também recebe influência em menor escala do Rio de Janeiro e da Bahia (GONÇALVES; FERREIRA, 2012, p. 3).

\footnotetext{
${ }^{2}$ Pessoas que procuram as religiões afro-brasileiras em busca de serviços mágicos, como fonte de solução para seus problemas, em sua maioria de ordem amorosa, financeira, doença física ou espiritual. Uma parcela de clientes torna-se adeptos. O termo clientes, faz jus ao comércio envolvido.
} 


\title{
1.10 catimbó/jurema
}

O catimbó/jurema figura como herança indígena que assimilou elementos negros ao longo do tempo. Para Bastide (2004), já existia, mais ou menos organizado, quando o negro chegou ao Brasil. Para Cascudo (1978), reúne elementos negros, brancos e ameríndios, porém se afigura, na sua concepção, como preponderantemente "magia branca", ou seja, de influência da feitiçaria e superstição popular europeias. ${ }^{3}$

$\mathrm{Na}$ Paraíba, temos vários registros de antigas mesas de catimbó, como por exemplo, nos bairros da Torre, Jaguaribe e Ilha do Bispo, além das cidades de Santa Rita, Alhandra/Acais (GONÇALVES, 2013). Tais registros mostram que em suas descrições iniciais não apresentam símbolos africanos, apenas indígenas e católicos. Mas com o passar do tempo sofrem mudanças.

O culto da jurema como é hoje praticado, apresenta diferenças significativas de como era feito até a década de 50. Hoje está bastante umbandizado, assumindo e incorporando elementos de várias fontes. Sobre a falta de elementos africanos nos cultos da Jurema, Gonçalves, revisando a literatura referente à questão, diz que a descrição feita pelos autores lidos,

\begin{abstract}
não registra a presença de sacrifícios de animais, rituais de iniciação, ligação com orixás, culto a exus e pombagiras presentes na jurema praticada hoje. [...] Embora preserve elementos das mesas dos mestres e do ritual indígena, está umbandizada. A sua identificação com a umbanda é tão forte, que na prática são tidas como sinônimo (GONÇALVES, 2013, p. 14).
\end{abstract}

Atualmente, muitos terreiros da cidade cultuam jurema e candomblé, para tal fazem quartos separados, sendo um dos orixás, o outro da jurema. Outras separações simbólicas podem ser descritas, como as diferentes vestimentas: na jurema predominam os tecidos estampados; no candomblé, quase sempre, branco ou a cor específica do orixá. A língua cantada: na jurema, o português; no candomblé, “ioruba”. Essas separações distinguem os rituais, o conjunto de crenças e cosmologia, o que, entretanto, não significa que entre eles haja pontos de convergência. Primeiro, são os mesmos agentes que praticam os dois cultos, utilizam o mesmo espaço físico (salão da casa) para realização dos rituais, e por último, contam com o mesmo público de clientes e frequentadores.

3 Fernando Giobelina Brumana, na obra já citada (GIOBELLINA BRUMANA, 2013), faz críticas contundentes às ideias de Bastide e Cascudo sobre o catimbó. 


\subsection{A umbanda e o candomblé}

Para analisar o candomblé é preciso entender suas origens, que estão na África da colonização, mas que também estão aqui no Brasil, afinal é brasileiro esse modelo de candomblé, com o panteão de orixás unificado.

Basta nos remetermos à África da época da colonização: a organização social era feita a partir de grupos étnicos, onde cada etnia cultuava o orixá ou vodum ou inquice ${ }^{4} \mathrm{e}$ ancestrais daquela região, era a ele que cada um e cada uma fazia suas rezas e oferendas, sendo ele o protetor do clã.

Os negros que foram escravizados, ao chegar ao Brasil trouxeram consigo suas culturas, seus costumes étnicos, suas devoções. Encontraram aqui outros grupos, de outros clãs, reorganizando no Brasil o culto aos seus ancestrais:

O candomblé brasileiro não se assenta sobre estruturas sociais como o caráter
tribal africanas de onde originou-se como culto aos orixás e antepassados, os
eguns (Atanda, 1980; Fadie, 1970). A nação tribal, o clã, as linhagens e a
organização familiar como estrutura produtiva e unidade de culto, com seus
antepassados imemoriais, estão para sempre perdidos. Mas isso tudo não
impediu o candomblé nascido no Brasil de firmar-se sobre a ideia central da
origem mítica da pessoa conforme a tradição iorubana (Verger, 1973;
Abimbola, 1973) (PRANDI, 1991, p. 24).

Exatamente por não estar situado nesta estrutura tribal, que o candomblé surge como uma experiência brasileira, mantém elementos da cultura africana, outros elementos surgem, outros são ressignificados.

A vinda de pessoas escravizadas resultou não somente na construção de uma "nova" cultura, mas em um novo formato de organização social desses povos, originando assim, aquilo que antes foi denominado calundu, e hoje é Candomblé, com diversas subdivisões, denominadas de nações por seus adeptos na busca por uma reaproximação com o continente africano. Assim, o candomblé brasileiro apresenta suas variações: jeje, jeje-marim, efã, fon, ketu, angola, tambor de mina, xambá, ijexá, batuque, entre outras denominações, do que compõe o quadro das religiões afro-brasileiras. Resultado dos processos diaspóricos:

\footnotetext{
${ }^{4}$ Os três termos correspondem ao panteão de divindades africanas. Sendo "orixás" o termo utilizado pela nação ketu, "voduns" pela nação jeje e "inquices" pela nação angola. "Ketu", "Jeje" e "Angola" são diferentes nações dentro do candomblé.
} 
Portanto, é importante ver essa perspectiva diaspórica da cultura como uma subversão dos modelos culturais tradicionais orientados para a nação. Como outros processos globalizantes, a globalização cultural é desterritorializante em seus efeitos. Suas compreensões espaço-temporais, impulsionadas pelas novas tecnologias afrouxam os laços entre a cultura e o lugar (HALL, 2009, p. 36).

Era uma religião originalmente negra, que foi reprimida ao longo da história, desde as senzalas até os dias atuais, e tem como referência simbólica a Bahia, com os mais famosos terreiros de candomblé do Brasil: a Casa Branca do Engenho Velho (considerado o mais antigo), que deu origem aos outros dois, Opô Afonjá e o Gantois. Eles representam o modelo nagô, bastante estudado e consagrado pelos cientistas sociais como Nina Rodrigues, Bastide, Verger, Edson Carneiro, Juana Elbein etc. Mas além desse modelo, na Bahia há outras casas tão antigas e importantes na disseminação do povo de santo pelo Brasil, como o Bogum e o Bate-folha.

Outros locais com bastante expressividade na tradição do candomblé são Recife/Olinda com o tradicional Sitio de Pai Adão, e o Maranhão com a Casa das Minas, além do Rio Grande do Sul com sua tradição do batuque.

Independente da nação, sabemos que o candomblé nasce e cresce em todo país como religião de negros, pobres e suburbanos. No início, praticada às escondidas nas senzalas dos senhores de engenhos, camuflado pelo sincretismo católico; após a libertação dos escravos, sua cultura vai aonde vão os negros, ou seja, para margem da sociedade. ${ }^{5}$

Porém, a liberdade para os escravos libertos, não tinha o mesmo significado que tem para a população em geral de hoje, como registra Cunha:

Era comum a assimilação abusiva de escravos e libertos negros. A polícia, em todo caso, não parecia fazer distinção. Na Paraíba, em 1844, escravos ou negros livres achados nas ruas depois do entardecer 'sem ordem de seus senhores' (mas que senhores, nesse último caso?) eram levados à delegacia de polícia e açoitados (CUNHA, 2012, p.113, grifos da autora).

No documento analisado pela autora, temos um bom referencial de como o negro era suprimido de sua liberdade, inclusive de sua liberdade religiosa, pois por muito tempo pós-escravatura, o candomblecista disfarçou-se de católico para garantir a sobrevivência de sua crença.

\footnotetext{
${ }^{5}$ Atualmente há um debate sobre a elitização do candomblé, como também o aumento da adesão de pessoas brancas ao seu quadro. Ver Capone (2009, p. 138).
} 
Para se viver no Brasil, mesmo sendo escravo, principalmente depois sendo negro livre, era indispensável antes de mais nada ser católico. Por isso, os negros que recriaram no Brasil as religiões africanas dos orixás, voduns e inquices se diziam católicos e se comportavam como tais. Além dos rituais de seus ancestrais, frequentavam também os ritos católicos. Continuaram sendo e se dizendo católicos, mesmo com o advento da República, quando o catolicismo perdeu a condição de religião oficial (PRANDI, 2003, p.16).

\title{
1.3 Nos caminhos da umbanda
}

Com a República, a religião católica perde o status de religião oficial, há uma separação legal entre Estado brasileiro e a Igreja Católica, (mas culturalmente a Igreja Católica continuava a exercer influências políticas). Abrindo portas, a partir da legalidade, para afirmação e posicionamento de outras religiões. Porém, na prática, a perseguição política ou repressão policial permaneciam, pois se havia a liberdade de crenças, não se efetivava na liberdade de culto.

A partir desse marco, a umbanda se institucionalizou. Conforme história consagrada na literatura, surgiu na década de 1920, com o registro de um centro de umbanda no Rio de Janeiro, conduzido por Zélio de Morais ${ }^{6}$. Era apenas um passo para disseminação da religião brasileira, com traços indígenas, europeus e africanos.

\begin{abstract}
A fundação, nos anos 20, daquele primeiro centro de umbanda no Rio de Janeiro como dissidência pública e institucionalizada do Kardecismo num processo de valorização dos elementos nacionais - o caboclo, o preto-velho, espíritos de índios e escravos - deve ter representado uma forma de acomodação seletiva entre os dois polos fundantes. Um movimento de rearranjo entre duas alternativas não conflitantes, embora uma mais rica em conteúdos doutrinários e a outra mais centrada em práticas rituais. O kardecismo como religião ética, de salvação, e o candomblé como religião ritualística e mágica, de manipulação do destino através de poderes sobrenaturais de que os sacerdotes são dotados por iniciação (PRANDI, 1991, p. 49).
\end{abstract}

Essa religião nascente, que promete ser a religião genuinamente brasileira por englobar elementos de diferentes culturas, aos poucos vai distanciando-se do candomblé, ou seja, dos "elementos negros":

[...] a umbanda nasceu no Rio de Janeiro nos anos 1920, bem como a preocupação de purificar o culto dos elementos mais próximos da tradição iniciática e sacrifical do candomblé. A língua portuguesa tomou o lugar da língua africana, a iniciação foi simplificada e quase eliminada, e os sacrifícios de animais foram condenados. $\mathrm{O}$ panteão do candomblé, reduzido a

\footnotetext{
${ }^{6}$ Ver Capone (idem, p. 133)
} 
"entidades" que se encarnavam nos médiuns deixaram de ser os orixás, para se tornarem os caboclos, os pretos-velhos, bem como os exus e pombagiras que "baixavam" para "trabalhar", isto é, para dar conselhos aos homens (CAPONE, 2009, p.133).

Seguindo os passos do kardecismo, a umbanda logo se espalhou, atravessando fronteiras dos estados brasileiros. Expandindo-se rapidamente, angariando adeptos tornou-se líder (em quantidade de fiéis) no campo das religiões afro-brasileiras. "Pelo menos desde a década de 1950, a umbanda tem sido majoritária no conjunto afrobrasileiro. [...], logo se espalhou pelo Brasil como religião universal sem limites de raça ou etnia, geografia ou classe social” (PRANDI, 2003, p. 19-20). Também,

\begin{abstract}
de um outro prisma, o kardecismo é uma religião de transe, da experiência religiosa pessoal, e ao mesmo tempo uma religião da palavra, da pregação doutrinaria codificada em livros religiosos de autoridade incontestável. Dotado de um código moral e doutrinário explícito e de procedimentos condutores da experiência religiosa públicos e publicados, a iniciação no kardecismo adotou uma pedagogia do não-segredo, do não mistério. Essa universalização contribuiu enormemente para uma acentuada unificação burocráticoinstitucional. A umbanda carrega consigo parte da norma dos candomblés, que é a do segredo, do recolhimento iniciático, da infalibilidade do pai-de-santo, da autoridade ex-cathedra do orixá acima de qualquer preceito, tendo por consequências enormes dificuldades de unificação doutrinária e institucional (PRANDI, 1991, p. 60).
\end{abstract}

A essa difusão da umbanda carioca, podemos atribuir "o esforço de uma elite de pensadores umbandistas, na ânsia de torná-la uma religião nacional" (GONÇALVES; FERREIRA, 2012, p. 7). Como já mencionamos anteriormente, é uma religião que se propõe a ser universal, ultrapassando os limites étnicos, aos quais estava preso o candomblé.

Na década de 1960, começam a acontecer mudanças no campo religioso afrobrasileiro, o candomblé que antes estava preso às amarraras étnicas e geográficas, ou seja, se limitava às regiões suburbanas onde se aglomeravam os descendentes de escravos, começa a romper com essas amarras, e foi "extravasando suas fronteiras geográficas, abandonando os limites originais de raça e etnia dos seus fiéis e ampliando seu território. Espalhou-se pelo Brasil, conquistando para seus quadros até mesmo antigos seguidores da umbanda. Nas pegadas da umbanda, também chegou ao estrangeiro" (PRANDI, 2003, p. 21).

Quando o autor afirma que o candomblé segue as pegadas da umbanda, pode-se levar a expressão em seu sentido literal, afinal os fiéis antes iniciados na umbanda passam 
agora a ser também candomblecistas, existindo assim um significativo trânsito religioso dentro do seguimento afro-brasileiro:

A circulação de médiuns ente os diferentes cultos parece ser um dos traços característicos desse universo. Reginaldo Prandi (1991) analisou a valorização do candomblé em face da umbanda e sua importante difusão na cidade de São Paulo durante os últimos anos. De fato, a umbanda, até os anos de 1970, parecia fadada a ser a religião mais importante dos grandes centros urbanos do Sudeste. O candomblé era tido apenas como uma origem longínqua da umbanda [...] (CAPONE, 2009, p. 135).

Dados do IBGE dos anos de 1991 e 2000, comparados por Prandi, apesentam essa adesão de maneira quantitativa. Mostrando que há possibilidade dentro do período analisado, de que adeptos declarados umbandistas em 1991 se auto declarem candomblecistas em 2000.

[...] em 1991, o candomblé já tinha conquistado 16,5\% dos seguidores das diferentes denominações de origem africana. Em 2000, esse número passou a $24,4 \%$. O candomblé cresceu para dentro e para fora do universo afrobrasileiro. Seus seguidores declarados eram cerca de $107 \mathrm{mil} \mathrm{em} 1991$ e quase 140 mil em 2000, o que representa um crescimento de $31,3 \%$ num período em que a população brasileira cresceu $15,7 \%$. Sem dúvida um belo crescimento. Por outro lado, a umbanda, que contava com aproximadamente 542 mil devotos declarados em 1991, viu seu contingente reduzido para $432 \mathrm{mil} \mathrm{em}$ 2000. Uma perda enorme, 20,2\% (PRANDI, 2003, p. 21).

A saída da umbanda para o candomblé pode ser vista de vários ângulos, levando em consideração que há uma ponte que diferencia a prática e os ritos dessas religiões, mesmo sendo ambas religiões de transe, suas organizações são diferentes, regras, preceitos, hierarquias e entidades. Prandi aponta três razões pelas quais, segundo ele, o médium faz a passagem da umbanda para o candomblé:

Primeira, a umbanda permite e incentiva um largo arco de criatividade. Ela sempre mostrou um elevado grau de receptividade para toda prática exotérica, para tantos níveis de combinação de símbolos e expressões. [...].

Segunda, a umbanda não conta com preceitos rituais ou doutrinais que sejam capazes de controlar o grau de liberdade de expressão do indivíduo, expressões individualizadas. Esta forma de expressar-se na umbanda conta com um inesgotável universo de entidades que podem se manifestar no transe ritual. Terceira, esta religião, apesar de sacerdotal, em que todos participam como oficiantes, não está contudo assentada numa hierarquia de senioridade iniciática na qual os adeptos possam se encaixar e se mover, tanto em termos de papéis específicos dentro do grupo de culto, como em termos de representação simbólica dos papeis sociais. Na umbanda todo mundo é igual, ela é até mesmo vista como exemplo de uma religião democrática (PRANDI, 1991, p. 88). 
Prandi coloca como sendo a própria umbanda a responsável pela perda dos adeptos, mas há outros fatores que podem ser evidenciados, componentes que foram construídos dentro da lógica do povo de santo. Observando que para os adeptos, ser do candomblé é sinônimo de força maior, ou seja, o candomblé teria mais poder mágico que a umbanda. Nessa lógica, referendada pelos praticantes das religiões afro-brasileiras, ser iniciado no candomblé é fonte de prestígio, status, poder.

Esse processo também está atrelado a uma mudança de paradigma do próprio candomblé, que em determinado momento da história passa a se impor como religião dentro do "mercado religioso", saindo dos guetos e tornando-se uma opção possível de ser acessada.

A saída do candomblé da invisibilidade releva o momento de reconstrução das identidades, ou como preferem os próprios agentes dessa história, de afirmação de uma identidade religiosa, que é ao mesmo tempo, negra e africana, ainda que, no seu meio, haja brancos, mulatos, mestiços etc. (GONÇALVES; OLIVEIRA, 2011, p. 127).

É nessa perspectiva da desetinização que Capone menciona a existência de dois tipos de negros e dois tipos de brancos, quando se fala sobre religiões afro-brasileiras. Fazendo uma oposição entre eles. Os dois tipos de negros seriam os nagô e os bantos. Os brancos: a aristocracia e a plebe (CAPONE, 2009, p. 138).

Em seu argumento, faz uma análise do cenário carioca, opondo o candomblé à macumba, dizendo que aquele é dos negros nagô que se sobrepõem aos frequentadores brancos aristocratas que são nele africanizados. Ao contrário do que ocorre na macumba dos negros bantos, onde a plebe branca os embranquece com a mestiçagem (CAPONE, 2009, p. 138).

Mas ao contrário do que se possa imaginar à primeira vista, africanizar-se não significa necessariamente se assumir negro, pois o processo de africanização no candomblé passa pela incorporação de outros elementos culturais como a língua, a vestimenta, comidas, títulos etc. Reginaldo Prandi, referindo-se aos terreiros de São Paulo, afirma que

[...] africanizar não significa nem ser negro, nem desejar sê-lo e muito menos viver como os africanos. Dos nossos, sessenta terreiros, 27 são chefiados por brancos. Destes, nove ostentam títulos religiosos conquistados em um ou mais templos nos países africanos que contêm os povos iorubanos (PRANDI, 1991, p. 118). 
Esse processo verificado em terreiros de São Paulo, atualmente parece se reproduzir nacionalmente. O objetivo principal é a busca incessante por verdadeiras origens, por legitimidade. Afinal, o que abrange o argumento que faz o candomblé dar um salto no "mercado religioso" é exatamente a ideia de legitimidade, de "religião verdadeira", aquela que "veio de África".

\begin{abstract}
Se seguirmos os passos daqueles que mudam de um axé para outro, veremos com expressiva frequência a busca de um novo terreiro que seja capaz de superar o anterior em termos de publicidade, fama, prestígio. Assim, mudança de axé, mudança de linhagem, significa também a procura por maior legitimidade para opção religiosa e, também um esforço de mobilidade ascendente que é a mobilidade social. A africanização como processo de religamento do candomblé à África contemporânea é uma forma que este novo candomblé de São Paulo encontrou para se libertar do velho e original candomblé baiano, e até mesmo superá-lo, criando sua própria originalidade e legitimidade. É necessária uma medida nova de importância e prestígio, e que não pode ser a antiguidade. Para completar esse movimento de autonomização em relação às velhas e tradicionais casas da Bahia, o candomblé de São Paulo tem assim necessariamente de reinventar-se também como tradição (PRANDI, 1991, p. 119).
\end{abstract}

Essa busca incessante pela tradição, pela legitimidade da tradição, passa pelo público que frequenta os terreiros. Capone falando sobre os dois tipos de negros e de brancos, acrescenta que o processo de africanização, no candomblé, ocorre com a presença da aristocracia branca, dos movimentos negros - uma certa elitização -, sem mencionar a presença de grupos universitários, tanto fiéis como estudiosos do candomblé. Aspecto também percebido por Reginaldo Prandi:

Africanizar significa também a intelectualização, o acesso a uma literatura
sagrada contendo os poemas oraculares de Ifá, a reorganização do culto
conforme modelos ou com elementos trazidos da África contemporânea
(processo em que o culto dos caboclos é talvez o ponto mais vulnerável, mais
conflituoso); implica o aparecimento do sacerdote, na sociedade
metropolitana, como alguém capaz de superar uma identidade com o baiano,
pobre, ignorante e preconceituosamente discriminado (PRANDI, 1991, p.118).

Outro ponto importante, no processo de reetinização do candomblé, é a sua assimilação como religião por questões político-ideológicas. Alguns seguimentos do movimento negro no Brasil incorporam a ideia de que para assumir-se como negro, identificar-se como tal, passaria também pela religiosidade, a qual, sem dúvida, seria a "religião de negros", o candomblé.

Compreendo a delicadeza dessa discussão, afinal, hoje, talvez o candomblé esteja mais ligado às amarras étnicas no discurso e menos na prática. Não poderia ser reetinizado 
categoricamente, pois, valendo-se do próprio argumento da prática religiosa, na qual todo ser humano é regido por um orixá, tudo leva à desetinização: se tem orixá, tem axé, logo tem candomblé.

\section{Pontos de encontro: as trajetórias e o campo religioso}

O processo que o campo afro-religioso vem passando em cenário nacional, tem se refletido no campo pessoense. Desde a chegada do candomblé à cidade, por volta de meados da década de 1980 (GONÇALVES, 2013, p. 2), inúmeros juremeiros e/ou umbandistas foram iniciados na religião, tornando-se seus adeptos, sendo que alguns abandonaram suas antigas denominações, enquanto outros agregaram o candomblé a fé preexistente.

O quadro abaixo - resultado da minha pesquisa de mestrado apresentada ao Programa de Pós-Graduação em Sociologia da Universidade Federal da Paraíba sintetiza a trajetória religiosa de cada interlocutor/a, desde a religião da família até as

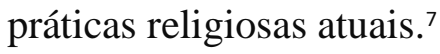

É possível, a partir dos discursos dos colaboradores, perceber certa lógica na qual o candomblé aparece como uma continuação da umbanda. A fala de pai $\mathrm{H}$ é um bom exemplo: "orixá queria mais, o que deram a ela na umbanda era pouco". Relata que ao chegar ao candomblé, o seu tempo de iniciado na umbanda foi levado em consideração para ser "promovido" no candomblé. Mas vale ressaltar que isso não é uma regularidade. Outro colaborador, ao chegar ao candomblé, juremeiro e pai de santo de umbanda, ainda assim teve que passar por todo o ritual de aprendizado como alguém que viesse de fora do campo.

Ainda nesse tópico, mãe XM percebe esse processo de continuidade de outra forma, ela faz ressignificações ao mencionar a descoberta do iorubá em seu universo simbólico: para ela, os rituais, as práticas são as mesmas da umbanda, possuem as mesmas funções, apenas regidas por outra língua, no caso, o iorubá.

Quadro: Caracterização da trajetória dos entrevistados ${ }^{8}$

\footnotetext{
${ }^{7}$ Refiro-me ao momento de realização da entrevista, meados de 2015.

${ }^{8}$ Preferi usar letras a nomes, ainda que fictícios, para não aproximar os entrevistados de outros sujeitos do campo religioso afro-brasileiro na cidade.
} 
TRAJETÓRIAS RELIGIOSAS ...

\begin{tabular}{|c|c|c|c|c|c|c|}
\hline & Família & $\begin{array}{c}\text { Religião } \\
\text { que } \\
\text { nasceu }\end{array}$ & \multicolumn{2}{|c|}{ Percurso } & \multicolumn{2}{|c|}{$\begin{array}{c}\text { Práticas } \\
\text { atuais }\end{array}$} \\
\hline $\begin{array}{c}\text { Mãe } \\
\text { XM }\end{array}$ & $\begin{array}{c}\text { Católica } \\
\text { catolicismo } \\
\text { popular } \\
\text { rezadores/ } \\
\text { evangélica) }\end{array}$ & Católica & $\begin{array}{c}\text { Rezadeira } \\
\text { Patolicismo } \\
\text { Popular) }\end{array}$ & Umbanda & Candomblé & $\begin{array}{c}\text { Rezadeira, } \\
\text { candomblecista, } \\
\text { cultua suas } \\
\text { entidades de } \\
\text { umbanda }\end{array}$ \\
\hline Pai H & Católica & Católica & Umbanda & Jurema & Candomblé & $\begin{array}{c}\text { Candomblecista } \\
\text { e juremeiro }\end{array}$ \\
\hline Pai I & Juremeira & Jurema & Umbanda & $\begin{array}{c}\text { Experiências } \\
: \\
\text { Kardecismo } \\
\text { Catolicismo } \\
\text { Evangelismo }\end{array}$ & Candomblé & $\begin{array}{c}\text { Candomblecista } \\
\text { e juremeiro }\end{array}$ \\
\hline Pai C & Católica & Católico & $\rightarrow \rightarrow \rightarrow \rightarrow \rightarrow \rightarrow \rightarrow \rightarrow$ & Candomblé & $\begin{array}{c}\text { Candomblecista } \\
\text { e católico }\end{array}$ \\
\hline Pai B & Católica & Católico & \multicolumn{2}{|c|}{$\rightarrow \rightarrow \rightarrow \rightarrow \rightarrow \rightarrow \rightarrow \rightarrow$} & Candomblé & Candomblecista \\
\hline
\end{tabular}

Fonte: Medeiros (2016, p. 110)

Tudo se passa como se o candomblé tivesse sido procurado pelos pais de santo de João Pessoa como forma de ascensão religiosa, fruto do discurso da herança africana, do maior poder mágico, da ancestralidade. Ainda nessa busca, o candomblé de João Pessoa voltou-se para Bahia, com a finalidade de beber na fonte da ancestralidade. Dois terreiros da cidade fizeram elos, anteriormente não existentes, com terreiros baianos, se auto intitulando descendentes diretos da Casa Branca (Gantois) e do Opô Afonjá, assim reforçando e legitimando seus axés.

Recentemente, ainda na busca pela ancestralidade, pelas origens, pela verdade, uma mãe de santo rompeu com esse modelo, voltando-se diretamente à África, movimento que vem sendo percebido em São Paulo (SILVA, 1995). Infelizmente essa senhora, recusou-se a participar da pesquisa. Sua trajetória nos ajudaria a visualizar melhor a dinâmica do campo, segmentado, aberto a outras possibilidades que podem vir a se tornar tendência.

\subsection{Uma Análise: traçando trajetórias religiosas no universo pessoense}

Segundo Bourdieu (2011, p. 103 ss.), a origem de uma trajetória social é fator determinante do habitus, é o seu ponto de partida. Quando uma trajetória é modal, seu 
fim tem um padrão do ponto de origem ao ponto de chegada, porém Bourdieu alerta para possibilidade de alterações provocadas pelas experiências vividas - para Lahire (2004), denominadas "experiências socializadoras".

Em nossa pesquisa, dois colaboradores têm trajetórias muito próximas em seu ponto de partida que se distanciam por meio de suas experiências socializadoras, são os casos de pai B e pai $\mathrm{C}$.

Eles pertencem à mesma geração, realidades sociais muito próximas, ambos perderam a mãe ainda na infância, têm como religião herdada o catolicismo, e na adolescência, conheceram o candomblé.

As trajetórias têm em comum o ponto de origem e o ponto atual, a divergência está na forma de construção da identidade religiosa de cada um. Quando pai B rejeita sua religião inicial, fazendo adesão ao candomblé, imprime mudanças em sua identidade a partir daquele ponto na sua trajetória, e essa experiência tem um peso enorme para sua subjetividade: afirma ter nascido novamente a partir da sua adesão ao candomblé.

O caminho oposto é tomado por pai $\mathrm{C}$, que não rejeita sua religião herdada, a ela associa uma nova cultura religiosa: passa por um processo de identificação, sem, porém, abandonar sua identidade anterior. A sua trajetória é bastante peculiar, pois acredita tanto no catolicismo quanto no candomblé. Justifica a associação a partir de elementos dos dois universos religiosos. No seu conjunto de práticas cotidianas, seu habitus cristão é extremamente presente, e algumas vezes, recorre aos elementos católicos para julgar e reprovar práticas e discursos do candomblé.

As escolhas de pai $\mathrm{B}$ e pai $\mathrm{C}$ fazem parte de um conjunto de possibilidades, que para Hervieu-Léger, não são infinitas. Como já mencionamos acima, em ambos os casos, o contexto tem um fator decisivo para o delineamento da trajetória. Foi necessário que o candomblé chegasse e se consolidasse no campo religioso, passando a disputar fiéis, principalmente, com a umbanda e o catimbó/jurema.

Essa chegada como possibilidade não invalida as outras, afinal como menciona pai B, a maioria dos seus amigos de escola, hoje é evangélica. Da mesma forma, nem todas as pessoas (clientes) que se consultaram com o caboclo de pai $\mathrm{L}$, hoje fazem parte do candomblé. Nesse ponto, Lahire (2004, p. 330) nos ajuda a compreender a ação do 
indivíduo, afirmando que suas ações são resultado da interação entre disposições e contexto.

Pai H, pai I e mãe XM passaram pela umbanda e procuraram o candomblé, com diferentes, realidades sociais distintas, trajetórias distintas. Quanto à geração mãe XM se distância dos demais em aproximadamente duas décadas. Mas nos três casos, a influência do campo é fator decisivo na adesão, cada um com motivações distintas: pai I e pai H buscam o candomblé como maior fonte de poder mágico; mãe XM, para solucionar problemas de saúde.

Mãe XM apresenta um intenso trânsito religioso. Saiu do catolicismo popular com influências familiares "na crença" (protestantismo), passou pela umbanda, e deu continuidade à vida religiosa no candomblé, sem, contudo, deixar as práticas de rezadeira, e sem abandonar suas entidades da umbanda.

Mãe XM parece exemplificar o que Bourdieu denomina habitus fraturado ${ }^{9}$, cujo resultado expressa-se nas associações que faz durante sua trajetória, mantendo disposições e o conjunto de crenças como rezadeira, umbandista e candomblecista.

O significado de habitus fraturado parte da ideia de frações de classe social, em que cada classe possui um habitus próprio, logo, cada fração tem um modo de agir conforme a parcela do capital que lhe é disponível/acessível (BOURDIEU, 2011, p. 106).

Considerando a impossibilidade de justificar as práticas a não ser pela revelação sucessiva da série dos efeitos que se encontram na sua origem, a análise faz desaparecer, em primeiro lugar, a estrutura do estilo de vida característico de um agente ou de uma classe de agentes, ou seja, a unidade que se dissimula sob a diversidade e a multiplicidade do conjunto das práticas realizadas em campos dotados de lógicas diferentes, portanto, capazes de impor formas diferentes de realização, segundo a formula: [(habitus) (capital)] + campo = prática. [...] Trata-se, portanto, de recompor o que foi decomposto, antes de mais nada, a título de verificação, mas também para encontrar, de novo, o que há de verdade na abordagem característica do conhecimento comum, a saber, a intuição da sistematicidade dos estilos de vida e do conjunto constituído por eles (BOURDIEU, 2011, p. 97)

No caso da nossa pesquisa, o capital em questão é o religioso, mãe XM, assim como pai I e pai H, têm sua prática determinada pelo capital adquirido ao passar pelas

\footnotetext{
${ }^{9}$ Sobre as clivagens do habitus, ver Bourdieu (2001).
} 
diversas experiências religiosas, multiplicado pela ruptura ou permanência do habitus original, adicionado à realidade do campo.

Pai $\mathrm{H}$ tem semelhanças em sua trajetória com mãe XM, visto que ambos partem de um catolicismo popular. A mãe biológica de pai H procurava a umbanda como fonte de serviços mágicos e soluções para os problemas espirituais e físicos que o catolicismo não lhe proporcionava, ocorrendo deste modo seu primeiro encontro formal com a umbanda. $\mathrm{O}$ contexto foi decisivo em suas escolhas, considerando a proximidade física de sua residência com o primeiro terreiro de umbanda que frequentou. Ambos rompem com o catolicismo, aderem à umbanda e, posteriormente, são iniciados no candomblé.

O que distingue suas trajetórias são as motivações, pai H está em uma busca de conhecimento, informações mais profundas, legitimidade e reconhecimento dentro do campo religioso afro-brasileiro; mãe XM busca uma cura, tanto na umbanda como no candomblé. Outra distinção decisiva em suas trajetórias é quanto à jurema. Mãe XM cultua até hoje suas entidades que trouxe da jurema via a umbanda; pai $\mathrm{H}$, ao contrário, rechaça sua história na umbanda, mas não despreza a jurema, apesar de perceber que entre elas há uma proximidade muito grande.

Poderia arriscar que esse recorte geracional que há entre os dois, precisamente 21 anos, reflete mudanças no campo afro-religioso da Paraíba, ao fazer adesão ao candomblé a mãe de santo junta seus conhecimentos dos orixás trazidos da umbanda aos conhecimentos adquiridos no candomblé, cultuando as entidades em momentos específicos.

O processo inverso acontece com o colaborador mais novo do grupo (pai H). Diz que na casa onde foi iniciado - casa de umbanda - sua pomba-gira, seu exu e seu mestre comeram para lhe dar uma segurança na jurema. O processo foi finalizando em uma segunda casa de umbanda que chegou a frequentar.

Em seu relato, é possível perceber a aproximação entre a jurema e umbanda (às vezes, tratadas como sinônimo), porém, há outra possibilidade discursiva, como a que apresenta pai I, para ele, a jurema seria algo independente da umbanda, trata-se de outra tradição. $\mathrm{O}$ fruto dessa independência serve para justificar a distância com a umbanda (atualmente com menor prestígio no campo), afinal, tanto pai I quanto pai $\mathrm{H}$ realizam cultos de jurema em seus terreiros, nos quais iniciam seus filhos de santo. 
A trajetória de Pai I é a mais atípica do conjunto, é a que mais se aproxima da figura do peregrino, conforme Hervieu-Léger (2008, p. 89). Ele tem uma religião definida (candomblé), mas seu sistema de fé é construído a partir de suas experiências em vários segmentos religiosos como kardecismo, catolicismo, evangelismo, além da umbanda e jurema (estas que são suas denominações de origem).

É ele que nos mostra que um sistema de fé pode sofrer alterações sempre que necessário ou sempre que as experiências socializadoras permitirem, lembrando que em seu relato, ele aventa a possibilidade de abandonar a sua atual religião. Não deixa claro, entretanto, se a deixaria para se tornaria um "sem religião" ou praticante de outra.

Retomando o conceito de trajetória, sabemos que Bourdieu afirma que todo campo tem uma trajetória modal, um padrão que afeta a maior parte dos sujeitos de uma classe ou de suas frações. Avalio essa perspectiva de dois modos: 1) o campo afro-religioso, em relação ao campo religioso como um todo, faz parte do conjunto de indivíduos que não seguem a trajetória padrão, percebendo-se que no censo de 2010, o conjunto da população brasileira que compreende umbandistas, candomblecista, espíritas e outros é de apenas 5\% da população do país. Fazer esse tipo de trânsito religioso ainda é uma escolha atípica, por mais que culturalmente seja fonte de soluções mágicas para os problemas espirituais, amorosos, financeiros e de saúde. A parcela que adere é pequena, e destes, aqueles que são declarados formam um grupo menor, porém, em crescimento devido ao processo de autoafirmação das religiões afro e as lutas contra a intolerância religiosa; 2) em relação ao campo afro-brasileiro na cidade de João Pessoa, também não é possível elaborar um padrão para as trajetórias, uma vez que os relatos, mesmo em pequeno número, apontam para isso. Todos possuem percursos diferentes que de alguma maneira os levaram ao candomblé.

A maioria tem origem no catolicismo, coincidindo com a história dos pais, por outro lado um dos interlocutores nasce dentro do campo afro-brasileiro, mostrando a consolidação do campo e abertura para a possibilidade de gerações atuais terem o candomblé como religião herdada. Dos quatro que apresentam o catolicismo como religião herdada, três deles rompem "definitivamente" com ele. 
A iniciação na umbanda aparece em três dos casos, na jurema, em dois. Nos casos de pai I e pai H, a jurema se sobressai nos relatos, mostrando como ganhou espaço e independência em relação à umbanda.

De acordo com o quadro apresentado, podemos visualizar melhor o percurso de cada colaborador da pesquisa. Sabendo que as motivações são distintas, porém cabendo em um número finito de possibilidades, vemos pai B e mãe XM buscando a religião como forma de conseguir a cura para seus males; pai I e pai $\mathrm{H}$ à procura de respostas e maiores poderes mágicos; e, pai $\mathrm{C}$, sem motivo aparente, foi se envolvendo lentamente com o contexto, a ponto de fazer gradual adesão ao candomblé.

\section{Considerações finais}

Concluir um trabalho não significa chegar ao final. Muitas janelas ficam abertas, enquanto algumas portas permaneceram fechadas, como o caso da mãe de santo que se recusou a colaborar com a pesquisa. Seu relato enriqueceria o trabalho, sabendo que sua trajetória agrega os mesmos elementos que os demais, ou seja, passou pelo catolicismo, kardecismo, umbanda, jurema, chegando ao candomblé. Foi uma das primeiras a aproximar-se de uma das casas da tríade do modelo nagô da Bahia.

Porém, tem uma peculiaridade em relação aos demais pais e mães de santo do candomblé pessoense: ela rompe com o modelo nagô e volta-se diretamente para África, aonde vai em busca da "religião verdadeira". Sua trajetória poderia ser apontada como um movimento possível dentro da perspectiva do religioso em movimento.

A pesquisa me levou pelo mesmo caminho já realizado por outros pesquisadores do campo, no qual se vê que a adesão/conversão religiosa é feita a partir de motivações pessoais, que podem ser percebidas coletivamente, ou seja, as motivações pessoais, que levam ao trânsito religioso, fazem parte de um repertorio clássico de dificuldades encontradas pelos sujeitos dentro de um determinado contexto, conduzindo-os a buscar soluções no transcendental.

Vimos que o repertório de motivações pessoais para mudança de religião engloba: a busca para cura de doença, em dois casos; ascensão religiosa, em dois casos, e a curiosidade no último caso. A adesão ao candomblé não significa o rompimento com a 
prática religiosa anterior, muito pelo contrário, ela é uma religião que não exige "exclusividade" do fiel, abrindo possibilidades para se agregar outras religiões.

Um elemento digno de destaque é a dupla pertença de pai C. Enquanto os demais romperam com o catolicismo - pai B e pai I não só romperam como afirmaram ser contra o sincretismo religioso - , ele mantém a fé católica, por escolha própria, firme e praticamente inalterada.

Outro ponto que chama atenção é o trânsito interno dos fiéis, ou seja, mudança entre casas da mesma denominação.

Pai $\mathrm{H}$ frequentou duas casas de umbanda, e teve dois zeladores ${ }^{10}$ de candomblé. O motivo de abandoná-los foi algum tipo de desentendimento pessoal com o pai ou irmãos de santo, ou clientes. Pai I passou por três casas de candomblé, (das nações ketu e angola): iniciou-se na casa de pai B, mudando-se em seguida para outra casa, com a possibilidade de regressar à casa de pai $\mathrm{B}$, se fosse vontade de seu orixá. Os motivos arrolados foram, no primeiro caso, mudança do pai de santo para outro estado brasileiro, no segundo caso, um desentendimento pessoal com seu zelador.

Mãe XM e pai C fazem apenas um trânsito dentro do candomblé, saindo de uma casa e indo para a de pai B. Ambos apontam a distância geográfica do primeiro terreiro como motivo da mudança.

Pai B é o caso mais específico em termos de trânsito interno. Faz sua iniciação com determinado babalorixá, passa pela casa de outros dois pais de santo até chegar ao terreiro frequentado atualmente. Para ele, o trânsito tem como peculiaridade a busca consciente por sacerdotes baianos, e preferencialmente por uma mãe de santo, ou seja, um axé feminino.

Essas experiências nos mostram o quanto é corriqueiro e comum mudar de casa dentro do candomblé, seja por desavenças com os babalorixás ou com outra pessoa da casa, por mudança de endereço, por não adaptação às regras internas etc. Sem dúvida, este é um tema que merece uma pesquisa específica.

${ }^{10}$ Zelador — aquele que zela pelo orixá. Sinônimo de pai de santo/ babalorixá. 
Um fator que pode explicar essa intensidade de trânsito interno do campo afrobrasileiro, quando comparado ao campo religioso como um todo, é a fluidez das regras do candomblé, pois cada casa tem um conjunto de regras próprias, sendo a autoridade máxima da casa o seu babalorixá/ialorixá. Logo, cada casa tem uma autoridade tão importante quanto a outra, capaz de acrescentar ou suprimir regras. Um adágio próprio do campo diz que "cada pai de santo tem seu tempero", indicando que é legitima a condução da casa conforme convenha a/o líder; ressalva feita aos rituais, que têm um mínimo de estrutura estabelecida como forma de reprodução da religião.

\section{Referências}

BASTIDE, R. Catimbó. In: PRANDI, R. Encantaria brasileira: o livro dos mestres, caboclos e encantados. Rio de Janeiro: Pallas, 2004, p. 146-159.

BOURDIEU, P. A economia das trocas simbólicas. 3. ed. São Paulo: Editora Perspectiva, 1989.

BOURDIEU, P. Meditações pascalianas. Rio de Janeiro: Bertrand Brasil, 2001.

BOURDIEU, P. A distinção: crítica social do julgamento. 2. Ed. Porto Alegre: Zouk, 2011.

GIOBELLINA BRUMANA, F. La jurema y otras yerbas: estudios sobre el campo religioso brasileño. Cádiz: Servicio de Publicaciones de la Universidad de Cádiz, 2013.

CAPONE, S. A Busca da África no candomblé. Rio de Janeiro: Pallas, 2009.

CASCUDO, C. Meleagro. Rio de Janeiro: Agir, 1978.

CUNHA, M. C. Negros, estrangeiros: os escravos libertos e sua volta à África. 2.ed. São Paulo: Companhia das Letras, 2012.

GONÇALVES, A. G. B. Catimbó/jurema, umbanda e candomblé: o campo religioso afro-brasileiro em João Pessoa. Relatório de Pós-doutoramento apresentado ao Departamento de Antropologia da FFLCH/USP, 2013, (Mimeo).

GONÇALVES, A. G. B.; OLIVEIRA, R. Identidade, tradição e legitimidade nas religiões afro-brasileiras. Revista de Teologia e Ciências da Religião da Unicap, Recife, v. 1, n. 1, p. 125-140, 2011. Disponível em: www.unicap.br > ... > Gonçalves, Rosalira dos Santos Oliveira. Acesso em: 10/01/2013.

GONÇALVES, A. G. B.; FERREIRA, H. C. Catimbó, umbanda e candomblé: o campo religioso afro-brasileiro em João Pessoa. Simpósio Nacional da Abhr, 13., 2012, São Luís. Anais... São Luís: ABHR, 2012. v. 13, p. 01-14. Disponível em: http://www.abhr.org.br/plura/ojs/index.php/anais/issue/view/9. Acesso em: 10 nov. 2012. 
HALL, S. Da diáspora: identidades e mediações culturais. Belo Horizonte: UFMG, 2009.

HERVIEU-LÉGER, D. O peregrino e o convertido: a religião em movimento. Petrópolis: Vozes, 2008.

LAHIRE, B. Retratos Sociológicos: disposições e variações individuais. Porto Alegre: Artmed, 2004.

MEDEIROS, Gracila G. de. Trânsito religioso: a busca pelo candomblé em João Pessoa. 2016. Dissertação (Mestrado em Sociologia) - Programa de Pós-Graduação em Sociologia, Universidade Federal da Paraíba, João Pessoa, 2016.

PRANDI, R. Os candomblés de São Paulo. São Paulo: Hucitec, 1991.

PRANDI, R. As religiões afro-brasileiras e seus seguidores. Civitas, Porto Alegre, v. 3, n. 1, p. 15-33, jun. 2003. Disponível em: http://revistaseletronicas.pucrs.br/ ojs/index.php/civitas/issue/view/5. Acesso em: 10/11/12.

SILVA, V. G. Orixás da metrópole. Petrópolis: Vozes, 1995.

Recebido em: 07/08/19.

Aceito em: 18/03/20. 